\title{
Assisting the development of innovative responsive façade elements using building performance simulation
}

\author{
M.L. de Klijn-Chevalerias ${ }^{1}$, R.C.G.M. Loonen' ${ }^{1}$, A. Zarzycka ${ }^{1}$, \\ D. de Witte $^{2}$, M.V. Sarakinioti ${ }^{2}$ and J.L.M. Hensen ${ }^{1}$ \\ ${ }^{1}$ Eindhoven University of Technology \\ Eindhoven, The Netherlands. \\ m.1.d.klijn@tue.nl \\ ${ }^{2}$ Delft University of Technology \\ Delft, The Netherlands.
}

\begin{abstract}
Thermal mass is usually positively associated with energy efficiency and thermal comfort in buildings. However, the slow response of heavyweight constructions is not beneficial at all times, as these dynamic effects may actually also increase heating and cooling energy demand during intermittent operation or can cause unwanted discomfort. This study investigates the potential of energy simulations to support the exploration-driven development of two innovative responsive building elements: "Spong3D" and "Convective Concrete". Both use fluid flow (Spong3D: water, Convective Concrete: air) inside the construction to reduce building energy demand by exploiting the use of natural energy sinks and sources in the ambient environment, aiming to make more intelligent use of thermal mass. During the development of these concepts, different simulation tools were used alongside experiments for e.g. materials selection, climate analysis, comfort prediction and risk assessment. By presenting the results from a series of simulation studies and by reflecting on their application, this paper shows how computational building performance analyses can play a useful role in ill-defined R\&D processes.
\end{abstract}

\section{Author Keywords}

thermal mass; adaptive façade; building simulation; energy performance; thermal comfort; design decision support; product development; physics-based simulation in design.

\section{ACM Classification Keywords}

Design; Experimentation; Performance.

\section{INTRODUCTION}

Over the last decades, building performance simulation (BPS) has evolved to become an established tool for supporting the design and operation of high-performance buildings [4]. BPS facilitates analysis of the interrelated effects of building shape, construction type, materials, energy systems, weather influences and occupant behavior on building performance. The potential of BPS is most pronounced when it is proactively used for guiding building design decisions towards solutions that combine high indoor environmental quality (thermal, air quality, visual, acoustic) with minimum use of resources (e.g. $\mathrm{CO}_{2}$ emissions or materials) [5]. However, the traditional, and still most common use of BPS is the application by engineers, for "post-rationalization" and code compliance at a time in the building design process when many influential design decisions have already been made $[1,2]$.

In an abstract way, the building design process can be described as the activity of conjoining various spatial configurations with different combinations of existing components, technologies and building material assemblies until a solution is found that satisfies all aesthetic and functional requirements [23]. This tendency of selecting from a collection of known or proven solutions often gives little room for conceiving truly innovative building concepts that reconsider the way in which buildings operate. It is increasingly realized, however, that such breakthrough innovations are necessary to meet the $21^{\text {st }}$ century societal and environmental challenges for a sustainable built environment [12]. Building envelopes and utilization of thermal mass play a crucial role in this respect, and the concept of adaptive facades has regularly been identified as being among the most promising developments and trends [7, 11, 18]. As such, there is a growing need to devise innovative façade concepts, with special attention for transforming them into scalable building envelope elements and products, to be able to achieve the biggest overall impact.

Such developments tend to start small but in large numbers. Through projects in architecture schools, design competitions and also in research projects with more technical orientation and via start-ups, a nearly incessant stream of new ideas and proposals for innovative adaptive façade concepts is being generated [15]. Judging from the information available in the public domain, it turns out that, despite its potential, BPS is rarely ever used to support such creativity-driven developments. The following barriers can be perceived:

- The explorative, iterative and diverging features of the R\&D process do not match with the analysis- and evaluation-oriented attributes of BPS. 
- Many simulation tools do not have the modeling capabilities required to predict the performance of certain novel adaptive features [16].

- There is a mismatch between (i) the amount and level-ofdetail of available information about the concept under development, and (ii) what is needed as input for BPS programs [14].

- The output options of simulation programs are perceived to be not informative for timely assistance in the decisionmaking process [19].

- The time required to obtain accurate predictions is incompatible with the need for quick feedback as the interpretation of the issue to be solved keeps evolving [8].

Despite the abovementioned barriers, the premise of this article is that, provided that it is used in a sensible and sometimes creative way, there is much scope for BPS as a support tool for decision-making throughout various phases of ill-defined, design-oriented R\&D projects of innovative responsive façade concepts. This potential will be demonstrated by presenting the development of two innovative building envelope concepts that both aim at making more intelligent use of thermal mass in buildings. These developments are part of the so-called 4TU.Bouw Lighthouse initiative. They are rather unique, multidisciplinary, one-year research projects, starting with an initial idea as outline, and leading to either a proof-ofconcept or proof-of-failure. This paper briefly presents the two concepts, demonstrates the use of BPS throughout various phases of the development, and concludes with a discussion and reflection about challenges and opportunities for more widespread use of BPS to support future innovation processes.

\section{CONVECTIVE CONCRETE}

\subsection{Concept}

The main goal of Convective Concrete is to mitigate residential overheating during summer periods by reducing the temperature of constructions through active heat exchange between the building construction and cool outside air at night. To accomplish the on-demand charging of thermal mass, a network of ducts (with attached fans) is embedded in a concrete wall element. This is done by developing customized formwork elements in combination with advanced concrete mixtures [6].

Using Fused Deposition Modeling (FDM), an Additive Manufacturing (AM) process based on material extrusion, the air channels are printed in wax so they can be placed in the formwork before casting the concrete and then be melted after the concrete is hardened (Figure 1). Consequently, the concrete is in direct contact with the air circulating through it and each air channel can be unique in form to optimize the performance of the system. To achieve an efficient activation of the concrete, the element functions like a lung. The convection takes place with separate pipes on both sides of the concrete's core to increase the charge/discharge of the thermal storage process. The airflow rate through the wall elements is controlled with the help of valves and small computer fans, as back-up for the buoyancy effect.
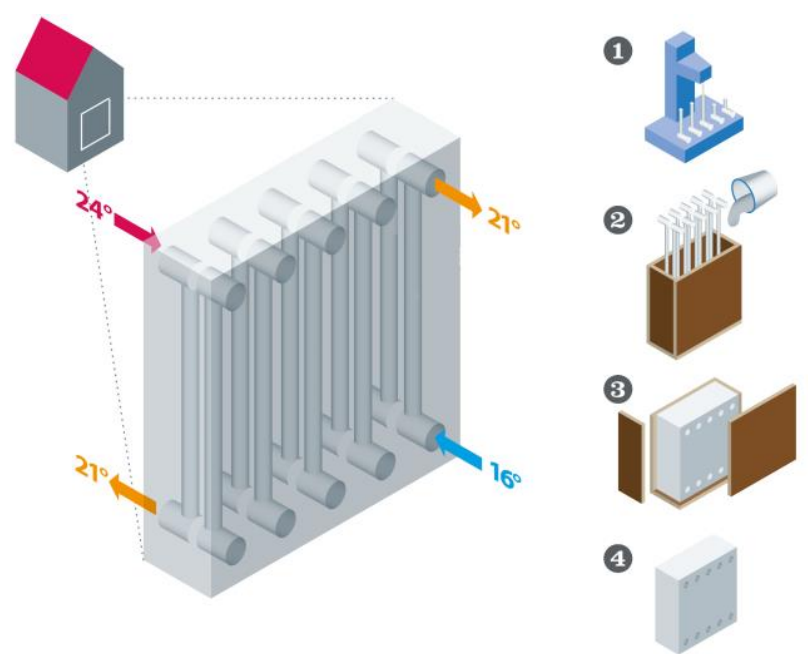

Figure 1. Convective Concrete concept.

\subsection{Simulation at the element scale}

Although the design process of the research uses experimentation with the making of mock-ups, not all parameters and design options can be extensively tested this way due to time and material constraints. However, computational simulations can help to make decisions on some variables in order to select the most promising properties to further analyze with the mock-up [17]. In this case, a two-dimensional dynamic heat transfer model is used via the simulation program Energy2D to make decisions on the shape and layout of the air channels in the Convective Concrete as well as the properties of the concrete mixture itself. The software program Energy2D is used to solve the dynamic Fourier heat transfer equations for the Convective Concrete case. Energy2D is a relatively new program [25] and is not yet widely used as a building performance simulation tool. To gain more confidence in the predictions with Energy2D, an analytical validation study was first carried out, inspired by the approach described by Hensen and Nakhi [10]. The simulation results never divert from the exact solution more than $0.45^{\circ} \mathrm{C}$ and it is therefore considered acceptable to further use this model [24].

Energy2D was then used to visualize the dynamic heat dissipation for various layouts of air channels. Different shapes, sizes and distributions of air channels were tested in a plan view and the isotherms are observed to determine the most efficient configuration. Figure 2 presents the comparison of aligned and staggered air channel distributions paused at the same time during the simulation. From this study, the first mock-up is designed with round air channels with a diameter of $4 \mathrm{~cm}$ which are aligned with a spacing of $8 \mathrm{~cm}$ between them. 


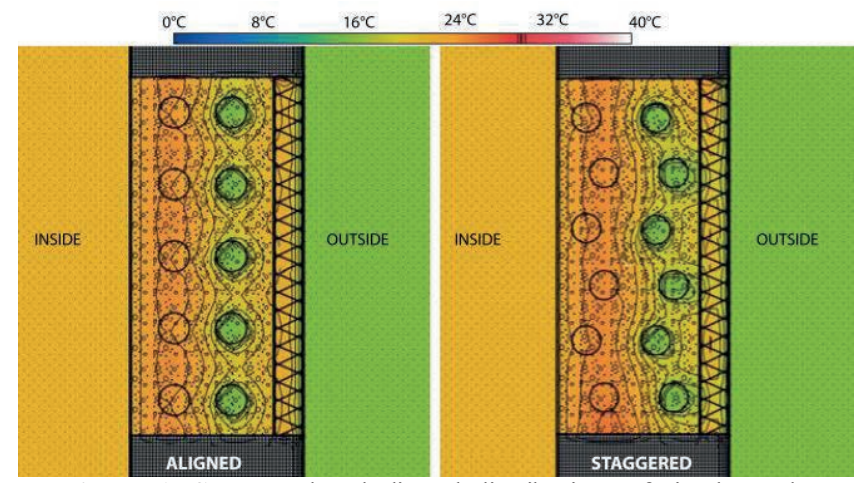

Figure 2. Staggered and aligned distribution of air channels

The Energy2D model is also used to characterize the thermal time constant of different concrete mixtures in order to select the mixture that will be used for the initial Convective Concrete mock-up. In this study, the temperature for a point in the middle of a $20 \mathrm{~cm}$ thick concrete wall is simulated and the wall is subjected to a $10^{\circ 00}$ temperature step decrease. The thermal time constant is defined as the time required for this point to change $\mathrm{e}^{-1}=$ $36.8 \%$ of the total difference between its initial and final temperature. The thermal time constant was evaluated for 70 existing types of concrete with different density and thermal conductivity. The heat capacity of the 70 types of concrete was always $840 \mathrm{~J} / \mathrm{kg}^{*} \mathrm{~K}$.

Figure 3 presents all the examined concrete types according to their thermal conductivity (x-axis) and their density (yaxis). The diameter of the circle represents the time constant recorded during the simulation for every concrete type while the shades of grey categorize the results in different sections of time. The smaller and darker the dot, the shorter the time constant.

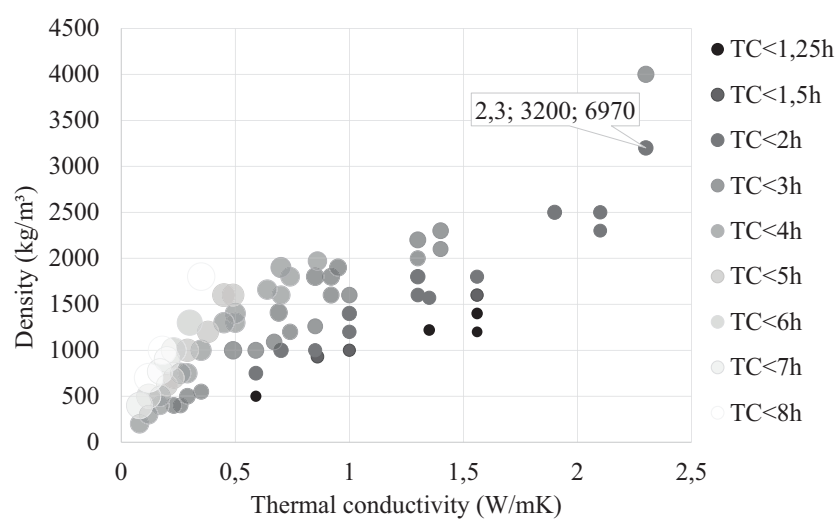

Figure 3. Thermal time constant of 70 concrete types.

This graph allows us to select a concrete mixture that has a high density for high storage capacity purposes while having a relatively quick thermal response with a time constant in the order of 2 hours. As can be seen in Figure 3, the selected concrete mixture has a density of $3200 \mathrm{~kg} / \mathrm{m}^{3}$, a thermal conductivity of $2.3 \mathrm{~W} / \mathrm{m} \cdot \mathrm{K}$ and a time constant of one hour and 56 minutes.

\subsection{Whole-building Simulation}

While the performance of the mock-up will be measured under controlled conditions, the timespan of the project does not allow to implement and monitor the performance of the system in a real building. This situation can instead be modeled in a whole building energy simulation software. No model pre-exists to simulate the innovative Convective Concrete system, however, some existing models have enough similarities and flexibility to replicate the effects of Convective Concrete.

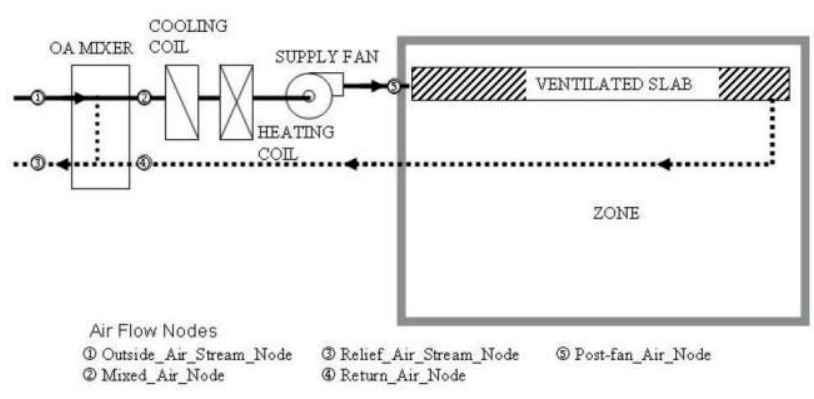

Figure 4. Schematic section representing the operation of the ventilated slab model in EnergyPlus [22].

In this study, the ventilated slab model developed by Chae and Strand [3] in EnergyPlus is used [9]. Since the Convective Concrete does not directly circulate the air of the room, the "Slab Only" mode which is displayed in a schematic manner in Figure 4 is selected. The system is assigned to wall surfaces rather than ceiling. Also, no heating or cooling coils are implemented as the Convective Concrete uses outdoor air directly.

Figure 5 shows the effect of Convective Concrete on a typical bedroom of $9 \mathrm{~m}^{2}$ when the system starts operating on day 2 at midnight (climate conditions: the Netherlands). The bedroom has two walls exposed to the outside: the south wall has a window while the east wall accommodates the Convective Concrete. Other surfaces are considered adiabatic. The outside air is circulated in the Convective Concrete element and out. This decreases the inside surface temperature of the wall which in turn decreases the temperature of the room. The ventilation in the Convective Concrete is only on when the outside temperature is low enough to cool the element which is mostly during the night. The thermal mass of the high density Convective Concrete keeps the room cool during the day.

With this model, various parameters can be altered in the simulation to visualize their effect. In Figure 5, a low (0.02 $\left.\mathrm{m}^{3} / \mathrm{s}\right)$ and high $\left(0.08 \mathrm{~m}^{3} / \mathrm{s}\right)$ air flow rate are tested. As expected, the high flow rate has a higher cooling effect, reducing the operative temperature up to 2 degrees. 


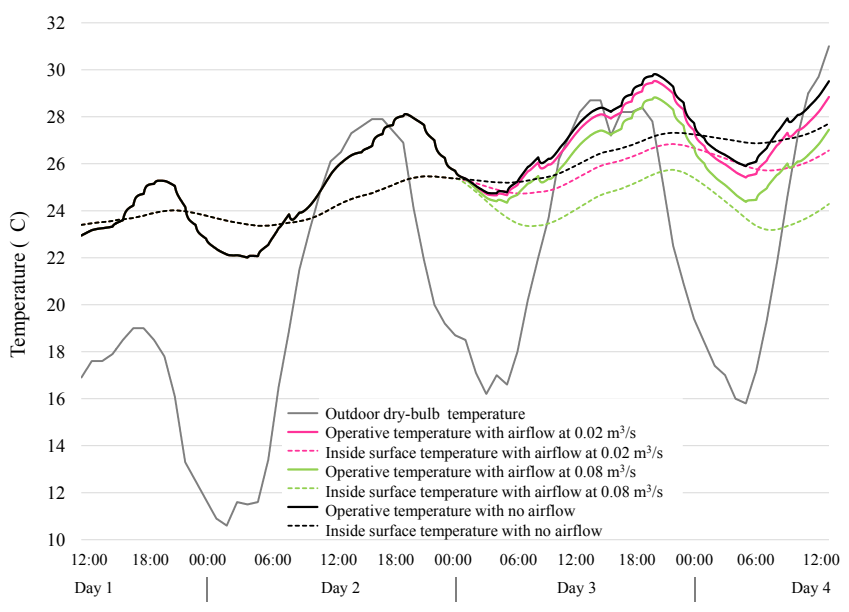

Figure 5. Effect of the Convective Concrete with an air flow rate of 0.02 and $0.08 \mathrm{~m}^{3} / \mathrm{s}$ compared to the system off.

The model also allows to analyze a longer period of time and different locations. To do this with measurements would require much more time and investments. Figure 6 presents the amount of time the operative temperature in the bedroom is above $24^{\circ} \mathrm{C}$ from the $1^{\text {st }}$ of April to the $31^{\text {st }}$ of October, for four different locations which are derived from the climate analysis (section 2.4). The baseline building has a typical brick cavity wall and the same insulation level as the Convective Concrete case. While the Convective Concrete was simulated with the same low and high air flow rate as in Figure 5, the baseline building was also modelled with the possibility to use free cooling by opening the windows at night (from $10 \mathrm{PM}$ to $6 \mathrm{AM}$ and when the temperature outside is at least 3 degrees lower than the temperature inside). For all locations, a high air flow rate is required to present significant improvement of thermal comfort compared to the scenario of opening the windows at night.

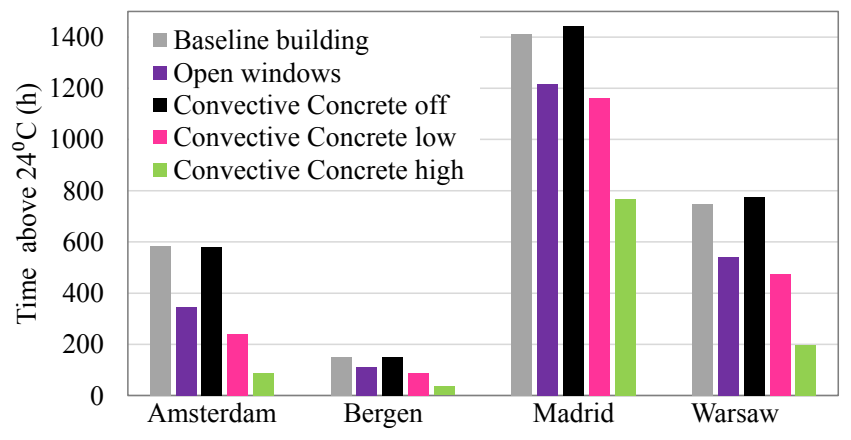

Figure 6. Hours above $24{ }^{\circ} \mathrm{C}$ for four locations.

\subsection{Climate analysis}

When developing a new building envelope system such as Convective Concrete, it is important to identify highpotential locations that have favorable climate characteristics with respect to the operating principles of the system. Convective Concrete is expected to work well in a climate where summer night time temperatures drop well below indoor comfort temperature. In this way, the outside air can effectively cool down the building structure, and help in reducing the extent of indoor overheating during the next day. In addition, it is important that the climate has a moderate degree of summer discomfort. Figure 6 shows that Convective Concrete is best used for peak shaving. For climates that have too little indoor overheating issues, it will be difficult to make Convective Concrete an economically viable investment. In climates that are too warm, on the other hand, buildings will likely rely on active cooling systems to ensure occupant comfort all year round.

Figure 7 shows temperature duration curves for eight European cities, inspired by Medved and Arkar (2008).

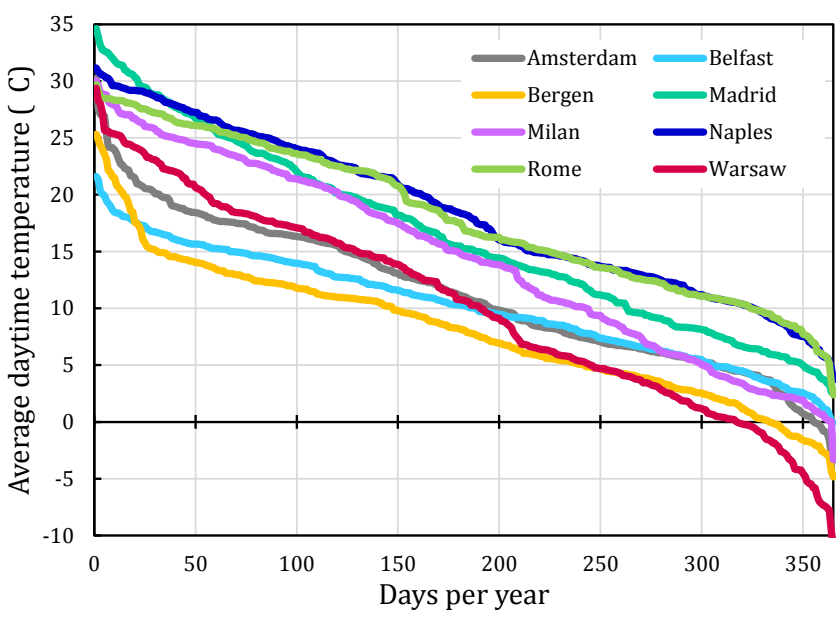

Figure 7. Temperature duration curves of average daytime $(08 \mathrm{~h} 00$ $-18 \mathrm{~h} 00$ ) outside temperature.

Each line represents the average daytime outside temperature, taken between $8 \mathrm{am}$ and $8 \mathrm{pm}$. The data is sorted from high to low values to investigate the number of days per year that a certain temperature is exceeded. The cities of Rome and Naples are considered as too warm for using Convective Concrete, since the average daily outside temperature is above $20^{\circ} \mathrm{C}$ for approximately half of the year. The climate of Belfast, on the other hand, has very mild summers, and consequently little need for summer cooling. The fact that both Warsaw and Madrid have continental climates, can also be observed since they both show a large temperature difference between summer and winter and a steep gradient. Bergen has a short, but rather intense summer season. Convective Concrete could be used to reduce indoor overheating during this period in cities such as Madrid, Warsaw, Bergen and Amsterdam.

To get a better understanding of the temperature difference between day and night, the daily amplitude in outside temperature was calculated for the four locations cited above (Figure 8). During the warmest period in Amsterdam and Warsaw, the temperature swing between day and night varies between 10 and $18^{\circ} \mathrm{C}$. On some days, this is enough to get a significant temperature difference for cooling down interior spaces. There are, however, also warm summer nights in which the free cooling potential will not be 
enough to avoid overheating. The city of Bergen has, on average, the lowest day-night temperature difference. Still, in the summer season, this difference is mostly above 10 ${ }^{\circ} \mathrm{C}$, indicating that there is potential for using free cooling. Madrid experiences a climate with warm summers, but also a large temperature difference between day and night. This seems to indicate that there is potential to use a low-energy cooling system such as Convective Concrete under these climatic conditions.

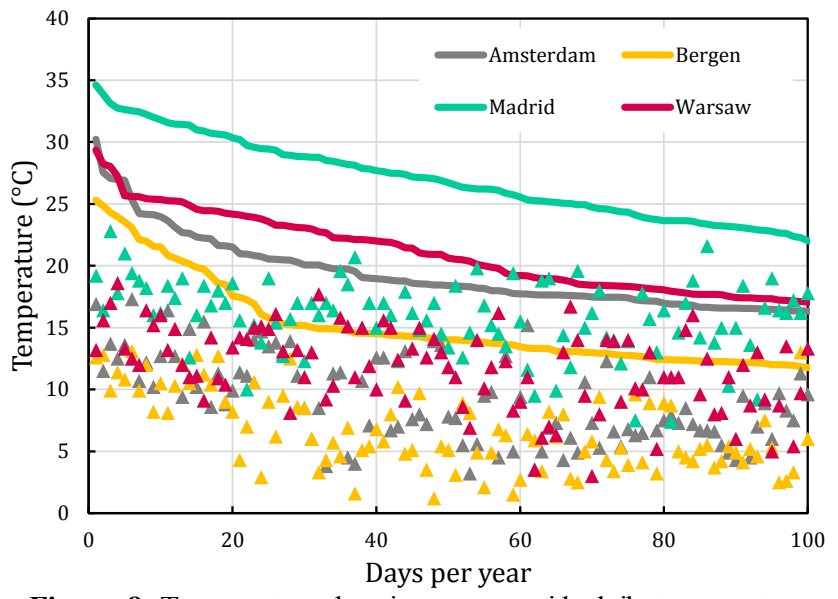

Figure 8. Temperature duration curves with daily temperature amplitude on the corresponding day.

This climate analysis provides an early estimate of the application potential of Convective Concrete in various European climates. Combined with dynamic building performance simulations, much more comprehensive information can be obtained to further predict the performance of the implemented system in our built environment (section 2.3).

\section{SPONG3D}

\subsection{Concept}

The Spong3D project investigates the potential of Additive Manufacturing to produce a façade system that fully integrates thermal insulation, heat storage, and distribution system additionally to traditional façade requirements [20].

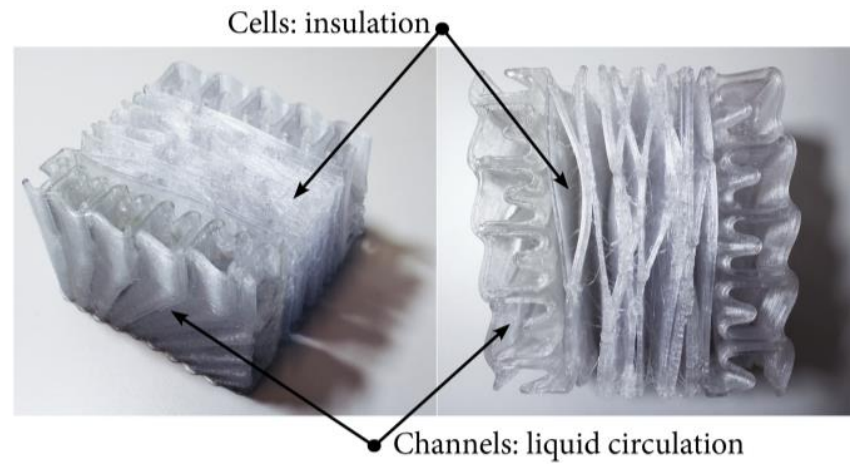

Figure 9. Sample of the structure with its channels and cells.

The proposed system incorporates closed air cavities which are located in the core of the façade to provide thermal insulation and channels on the outer layers which are used to circulate a liquid (water plus additive) that acts as thermal mass. Together, the composition of the channels and the cavities form a complex structure, integrating multiple functions into a single component (Figure 9).

Thanks to two reversible pumps, the liquid can be circulated from one side of the façade to the other with the possibility to be stored in a tank in the middle of each façade panel when necessary (Figure 10).

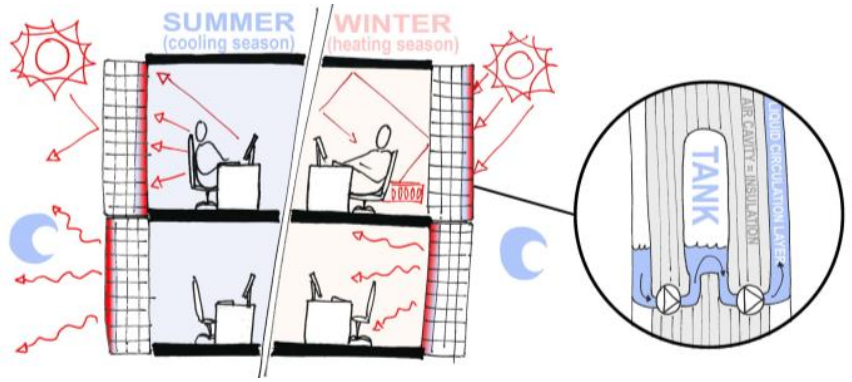

Figure 10. Schematic illustration of the operation of the system.

In a cooling situation, the liquid is first placed on the inside to absorb internal heat gain and is then pumped to the outside layer to discharge its heat to the cool night sky. For heating purposes, the liquid is placed outside during daytime, to absorb any solar heat gain and is then pumped to the inside to release this heat inside the building.

\subsection{Simulation at the element scale}

The multidisciplinary research team involves experts with various backgrounds, which ensures that every aspect of the requirements expected from the façade system is considered. In this research team, three main disciplines are highlighted: (i) design and 3D printing process, (ii) structural engineering, (iii) building physics and thermal performance. The structural engineers performed impact tests on the 3D printed material which showed unpredictable strength of the material depending on the printing conditions. A significantly higher number of tests was required to make safe conclusions about the resistance of the façade towards impacts. The structure team expressed its concerns and suggested to apply a glass cover on both sides of the façade element to guarantee its protection. On the other hand, the design team argued that adding a glass cover would restrict the freedom of shape allowed by AM. Multiple different arguments were presented by various team members, which made it difficult to make a clear decision on which direction to continue the research. Introducing a façade system that integrates many functions with a single material and manufacturing process is one of the main goals of this project. However, the first goal is to create a façade system that integrates controlled heat exchange, storage and distribution. Therefore the decision of having a glass cover should be determined based on the thermal performance of the system with and without it. 
At this stage of the design, Energy2D appeared as a suitable tool to quickly assess the effect of adding a glass cover relative to not having it. The façade was modeled in section in the 2-dimentional heat transfer model. The different parts of the system were modelled with layers of different properties as presented in Figure 11. The different scenarios (e.g. liquid on the outside during summer night) were modelled in different files and the absorption or release of heat was studied over time.

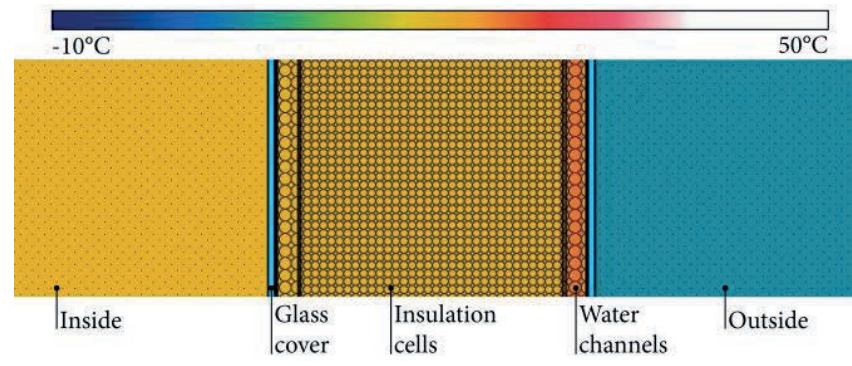

Figure 11. Model of the Spong3D system with glass cover in Energy2D (section)

For each scenario, the glass cover presented an extra thermal resistance which reduced the release or absorption of heat by the liquid layer in the first 10 hours. These simulations allowed to quickly produce quantitative results, leading to actionable information that allowed the research team to move on in a common direction.

\subsection{Whole-building simulation}

Similarly to Convective Concrete, as explained above, the Spong3D system does not correspond to any existing model from a whole-building simulation program. However, the water layer on the outside operates in a similar way as a solar collector does. It absorbs heat from solar radiation during sunny winter days and exchanges the thermal energy to a liquid with a specified mass flow rate. The same model can be used to investigate heat losses during cool summer night.

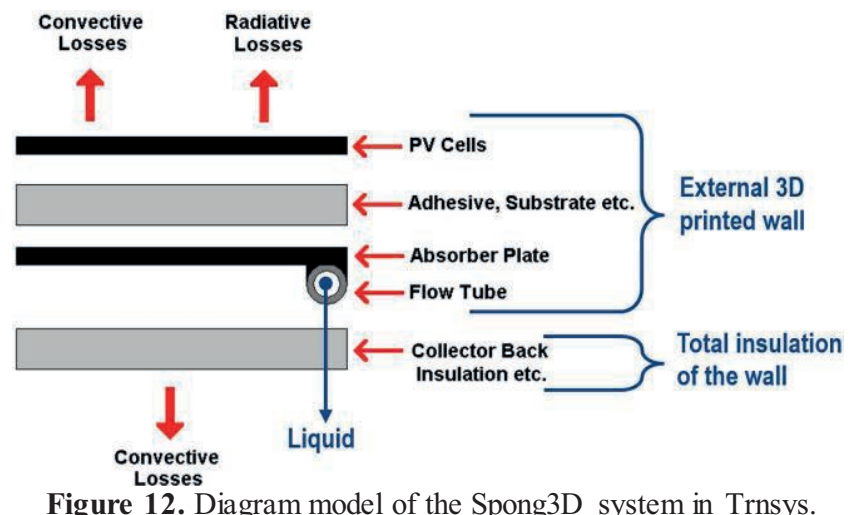

As explained previously, the solar collector model should be unglazed to reduce the resistance to heat transfer. Therefore, the component Type 560 in Trnsys was used. It models a combined PV/T solar collector [21]. As shown in Figure 12, the properties of the flow tube, absorber plate, adhesive, substrate and PV cells are modified to represent the properties of the $3 \mathrm{D}$ printed water channel wall which as a thermal resistance of $0.0092 \mathrm{~m}^{2} \mathrm{~K} / \mathrm{W}$.

The focus of the simulation presented here is on the summer night and winter day scenarios when the liquid is placed on the outer channels and interacts with the outside climatic conditions.

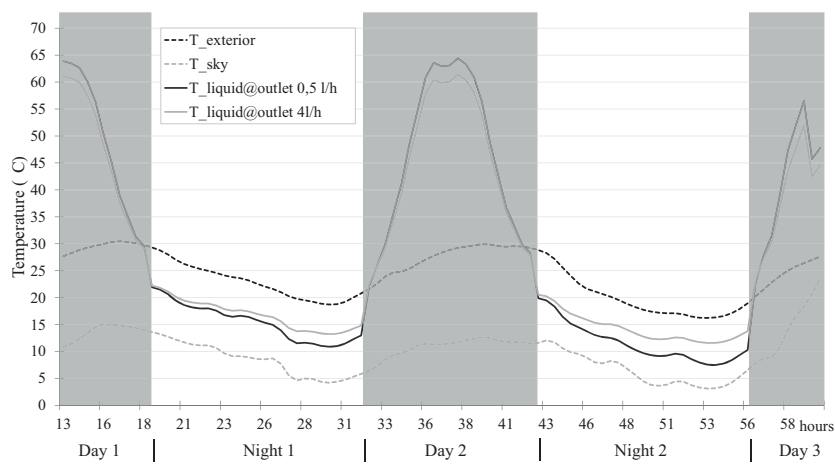

Figure 13. Trnsys results showing the temperature of the liquid during two summer night for two mass flow rate.

The weather file used in this simulation allows to observe the dynamic effects of the climate on the temperature in the channels. Until now, the different scenarios of the liquid being placed in the inner or outer channel layer are looked at separately. But the result of one simulation can be used as input for the other. This model allows to alter various parameters such as: thermal properties of the front cover, mass flow rate of the liquid, thermal properties of the liquid, outside climate conditions.

Figure 13 shows that a lower mass flow of $0.5 \mathrm{l} / \mathrm{h}$ releases more heat during the night than a high flow rate of $41 / \mathrm{h}$. A similar trend was observed for the scenario of a sunny winter day where a low mass flow rate of the liquid allows it to get warmer than with a high mass flow rate.

\subsection{Climate Analysis}

As mentioned in section 3.3, the system can be tested in different climate conditions. But simply looking at the weather files can already give a lot of information about the performance of the system in different locations.

As seen in Figure 13, the outside temperature, but more importantly the sky temperature will determine how easily the heat in the liquid will be released to the environment at night during the summer. In winter, it is important to look at the outside temperature and at the solar radiation since the Spong3D system would work best in locations with cold but sunny winter days. Figure 14 presents four color maps created with the Ladybug plug-in for Grasshopper [13]. Each pixel represents one hour of one winter day and is colored according to the legend on the right. The top chart shows the solar irradiance between 200 and $1000 \mathrm{Wh} / \mathrm{m}^{2}$ and the second from the top shows the dry-bulb temperature from -10 to $20{ }^{\circ} \mathrm{C}$, both for Amsterdam, the Netherlands. The two bottom charts show the same but for Toronto, 
Canada. As can be seen, the climate of Toronto benefits from longer and sunnier days than in Amsterdam while the temperature rarely goes above $10{ }^{\circ} \mathrm{C}$.

In conclusion the heating capacities of the Spong3D system in winter would be much more beneficial in Toronto than in Amsterdam as it could be used more often and yield a greater temperature difference.
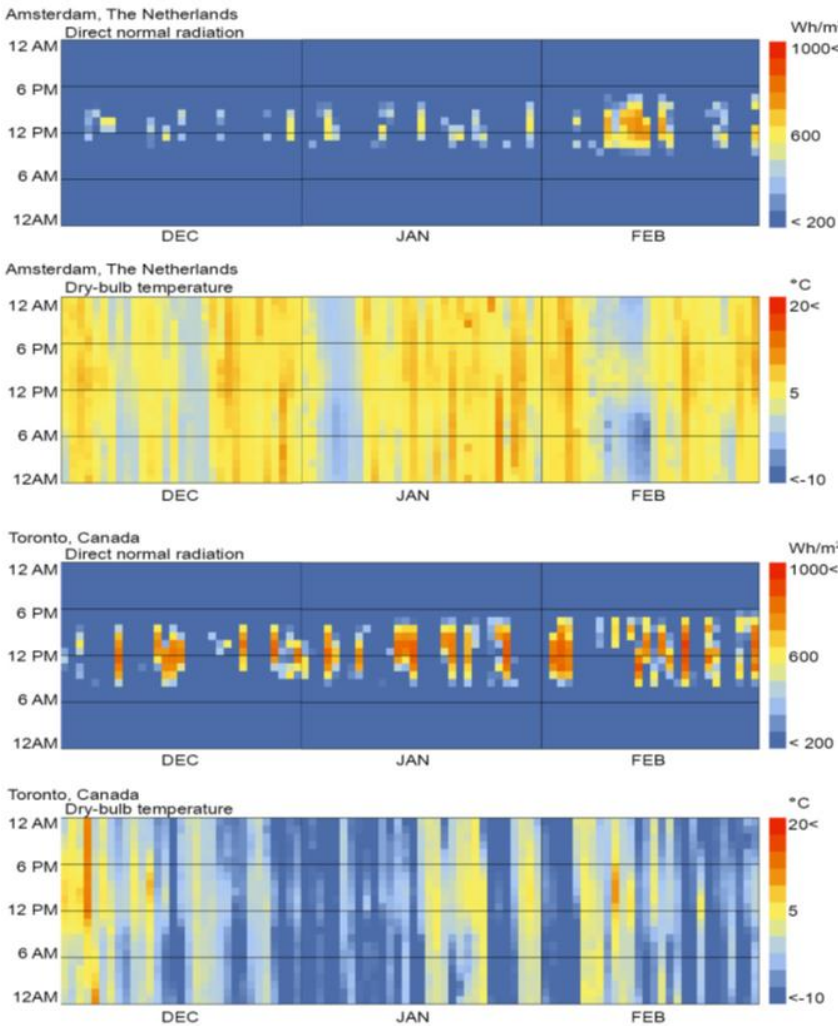

Figure 14. Radiation and temperature flood chart for Amsterdam (top) and Toronto (bottom).

\section{DISCUSSION AND CONCLUSION}

This paper has summarized the process and outcomes of simulation-based research activities in the development of two adaptive building envelope systems, with a focus on energy and comfort aspects. Different simulation strategies, with various software programs (i.e. Energy2D, Ladybug, Trnsys and EnergyPlus) were deployed in response to the needs posed by different questions in different phases of the R\&D process. The development of both concepts is still work in progress. Modelling and simulation will continue to play an important role in planned follow-up activities.

Literature shows that BPS is occasionally used to support decision-making in product development of innovative building envelope components in industry [17]. It was found, however, that its application in more explorative projects, such as the ones reported in this article, is rare. A perceived mismatch between simulation capabilities and the need for rapid feedback in relation to the ill-defined and evolving nature of explorative $R \& D$ projects is believed to inhibit the use of BPS in this context.
The various short simulation studies that have been presented throughout this paper, however, demonstrate that this assertion does not always have to hold true, because BPS can provide valuable feedback to the R\&D team, by:

- Providing quick estimates about the performance of multiple problem-solution pairs to offer early information that helps choosing among different development directions.

- Giving the R\&D team the opportunity to analyze the energy and comfort consequences of their decisions at multiple spatial scales, from material to whole-building level. The dynamic features of BPS are especially relevant, because due to the high influence of thermal inertia, simple calculation methods and rules-of-thumb may not suffice.

- Enabling the option to conduct virtual experiments and explore what-if scenarios (e.g. different climate conditions) in a quick and cost-effective manner.

- Helping in the definition and design of physical experiments that use available resources efficiently.

- Allowing for the exploration of the performance of materials and components with not-yet-existing properties. This is, evidently, not possible in experimental research.

- Confirming engineering intuition by means of quantitative metrics. Or alternatively, providing physicsbased insights in situations where counterintuitive effects are to be expected.

This type of information is not only helpful for making informed decisions when selecting between different design alternatives, it may also help in determining the longer-term outlook of the innovation. For example, simulations can provide quantitative input for business models and identification of high potential niche markets, as well as realistic projections for attracting possible follow-up funding.

It was also demonstrated that systematic analysis of datasets with typical meteorological weather data (TMY files) can lead to additional useful insights. Although the use of TMY files is strictly speaking not a simulation activity, it is closely related to the building simulation field, and therefore also considered in this paper. With the help of such climate analyses, it becomes easy to target most promising application areas, and to tune design specifications in response to these conditions.

Dealing with first-of-its-kind innovative façade concepts often means that the tools available for simulations on the whole-building scale do not have sufficient modelling capabilities to support performance evaluation of these specific elements. It should be noted, though, that many simulation models can be reused outside their initially intended application domain, as long as there is sufficient attention for quality assurance [16]. Using examples of the ventilated slab in EnergyPlus, and a BIPVT collector in 
Trnsys, this paper has demonstrated two examples of such a creative use of legacy simulation software.

Both projects that are discussed in this article make use of additive manufacturing as a production method for making prototypes as well as the final product. The application of $\mathrm{AM}$ as a rapid prototyping tool has led to many design iterations and a strong interaction with simulation activities. With the growing interest in $\mathrm{AM}$ in the construction industry, many promising opportunities are foreseen to further take advantage of the coupling with BPS.

There are several other trends in the field of computational building performance analysis, such as generative and parametric design methods, enhanced simulation domain integration (e.g. thermal, visual and airflow), advanced visualization techniques and the use of building information modeling. It is expected that these developments will help in further reducing the barrier for applying BPS in exploration-driven $\mathrm{R} \& \mathrm{D}$ projects.

\section{ACKNOWLEDGMENTS}

The authors want to thank 4TU.Bouw for its support in the form of two Lighthouse project grants. We are very grateful to all Lighthouse project members for many inspiring discussions and for creating the research environment in which this paper could develop.

\section{REFERENCES}

1. Attia, S., Gratia, E., De Herde, A. and Hensen, J.L.M. (2012). Simulation-based decision support tool for early stages of zero-energy building design. Energy and buildings, 49, pp.2-15.

2. Bernal, M., Haymaker, J.R. and Eastman, C. (2015). On the role of computational support for designers in action. Design Studies, 41, pp.163-182.

3. Chae, Y.T. \& Strand, R.K. (2013). Modeling ventilated slab systems using a hollow core slab: Implementation in a whole building energy simulation program. Energy and Buildings, 57, 165-175.

4. Clarke, J.A. and Hensen, J.L.M. (2015). Integrated building performance simulation: Progress, prospects and requirements. Building and Environment, 91, pp.294-306.

5. Clevenger, C.M. and Haymaker, J. (2011). Metrics to assess design guidance. Design Studies, 32(5), pp.431456.

6. Convective Concrete. www.4tu.nl/bouw/en/LHP2016/Convective Concrete

7. COST TU1403.(2017). EU COST Action TU 1403: Adaptive Façade Network, www.adaptivefacade.eu.

8. Dorst, K. and Cross, N. (2001). Creativity in the design process: co-evolution of problem-solution. Design studies, 22(5), pp.425-437.

9. EnergyPlus v8.4. www.energyplus.net
10.Hensen, J.L.M. and Nakhi, A.E. (1994). Fourier and Biot numbers and the accuracy of conduction modelling. Proceedings of BEP '94 Conference (pp. 247-256). York: Building Environmental Performance Analysis Club (BEPAC).

11. Hoes, P. and Hensen, J.L.M. (2016). The potential of lightweight low-energy houses with hybrid adaptable thermal storage: comparing the performance of promising concepts. Energy and Buildings, 110, pp.7993.

12.IEA (2013). International Energy Agency, Technology Roadmap: Energy Efficient Building Envelopes.

13. Ladybug. www.grasshopper3d.com/group/ladybug

14.Lin, S.H.E. and Gerber, D.J. (2014). Designing-in performance: A framework for evolutionary energy performance feedback in early stage design. Automation in Construction, 38, pp.59-73.

15.Loonen, R.C.G.M. (2017). Overview of Climate Adaptive Building Shells. Online: www.pinterest.com/CABSoverview

16. Loonen, R.C.G.M., Favoino, F., Hensen, J.L.M. and Overend, M. (2017). Review of current status, requirements and opportunities for building performance simulation of adaptive facades. Journal of Building Performance Simulation, 10(2), pp. 205-223.

17. Loonen, R.C.G.M., Singaravel, S., Trcka, M., Cóstola, D. and Hensen, J.L.M. (2014) Simulation-based support for product development of innovative building envelope components. Automation in Construction 45, 86-95.

18.Loonen, R.C.G.M., Trčka, M., Cóstola, D. and Hensen, J.L.M. (2013). Climate adaptive building shells: Stateof-the-art and future challenges. Renewable and Sustainable Energy Reviews, 25, pp.483-493.

19.de Souza, C.B. (2012). Contrasting paradigms of design thinking: The building thermal simulation tool user vs. the building designer. Automation in Construction, 22, pp.112-122.

20. SPONG3D. www.4tu.nl/bouw/en/LHP2016/SPONG3D

21. Trnsys v17. www.trnsys.com

22. U.S. Department of Energy (2016). Engineering Reference, EnergyPlusTM Version 8.5 Documentation. Section 17.6.16 Ventilated slab.

23.de Wilde, P. and Van Der Voorden, M. (2004). Providing computational support for the selection of energy saving building components. Energy and Buildings, 36(8), pp.749-758.

24.de Witte, D., de Klijn-Chevalerias, M.L., Loonen, R.C.G.M., Hensen, J.L.M., Knaack, U., Zimmermann, G. (2017). Convective Concrete: Additive Manufacturing to facilitate activation of thermal mass. Journal of Façade Design and Engineering, 5(1).

25. Xie, C. (2012). Interactive Heat Transfer Simulations for Everyone, The Physics Teacher, Volume 50, Issue 4, pp. 237-24. 